\title{
Cerebellar Culture Models of Dendritic Spine Proliferation after Transplantation of Glia
}

\author{
Fredrick J. Seil \\ Office of Regeneration Research Programs, VA Medical Center and Departments of Neurology and Cell and \\ Developmental Biology, Oregon Health Sciences University, Portland, OR 97201, USA.
}

\section{SUMMARY}

Studies of Purkinje cell dendritic spine proliferation after transplantation of cytosine arabinoside (Ara C) treated organotypic cerebellar cultures with glia and granule cells, either separately and in combination, were reviewed. Exposure of cerebellar explants to Ara $\mathrm{C}$ for the first 5 days in vitro results in the destruction of granule cells, the only excitatory cortical neurons, and oligodendroglia, and functionally compromises surviving astrocytes so that they do not appose neuronal membranes. In the absence of granule cells, there is a sprouting of Purkinje cell recurrent axon collaterals, the terminals of which project to and form heterotypical synapses with Purkinje cell dendritic spines, which are usually occupied by terminals of granule cell axons (parallel fibers). After this reorganization has been achieved, the explants can be transplanted with the missing elements to induce a second round of reorganization, with approximate restoration of the usual interneuronal relationships. Addition of both granule cells and glia resulted in a proliferation of clusters of Purkinje cell dendritic spines, which formed synapses with

\section{KEY WORDS}

Purkinje cells, granule cells, astrocytes, agranular cerebellum, synapses, axonal sprouting

\footnotetext{
Reprint address:

Fredrick J. Seil

ORRP (151 N), VA Medical Center

Portland, OR 97201, USA

Fax: +503-721-7906
}

axon terminals of transplanted granule cells, and as synapse formation progressed, the spine clusters became reduced. Transplantation of Ara C-treated cultures with glia alone resulted in a proliferation of clusters of Purkinje cell dendritic spines, but in the absence of granule cells the spines remained unattached, and the clusters persisted throughout the period of observation. Purkinje cell dendritic spine proliferation was induced by exposure of Ara Ctreated cultures to astrocyte-conditioned medium. When Ara C-treated cerebellar cultures were transplanted with granule cells in the absence of functional glia, parallel fiberPurkinje cell dendritic spine synapses formed, but no clusters of Purkinje cell dendritic spines were observed. These findings suggest that Purkinje cell dendritic spine proliferation is induced by an astrocyte-secreted factor, resulting in an expansion of postsynaptic sites available for synaptogenesis.

\section{INTRODUCTION}

The presence of Purkinje cell dendritic spines, the targets of parallel fiber (granule cell axon) terminals, has been reported in a variety of conditions in which cerebellar granule cells have been reduced or eliminated by different methods, including toxins $/ 10 /$, antimitotic agents $/ 13,14 /$, viral agents $/ 11,15,19 /, \mathrm{X}$-irradiation $/ 1 /$, and as a result of a genetic mutation, such as the weaver mouse $/ 12,21,39,40 /$. Some authors /19/ reported the density of such "unattached" or "naked" or "free" spines without presynaptic elements as increased per unit length of dendrite compared with normal Purkinje cells, whereas others /15/ referred to Purkinje cell dendrites as "very heavily laden" with spines. The naked spines were generally 
described as encased in astrocytic processes and possessing dense structures, similar to postsynaptic thickenings $/ 1,10-15,19,39,40 /$. The persistence of naked spines throughout the life span of weaver mutant mice $121 /$ indicated that presynaptic elements were not necessary for maintaining Purkinje cell dendritic spines. Most investigators felt that the presence of parallel fibers was also not necessary for the induction of dendritic spines $/ 12,15,19,21,40 /$, as spines developed in the absence of parallel fibers. Spine formation was interpreted by some authors as an autonomous property of Purkinje cells.

In a more recent study using cultures of dissociated Purkinje cells, dendritic differentiation was arrested when Purkinje cells were cultured in isolation $/ 2 /$. Dendritic branching, although of abnormal pattern and caliber, was achieved when Purkinje cells were cocultured with astrocytes, but the dendrites did not develop spines. The greatest dendritic branching plus spine formation occurred when purified Purkinje cells were cocultured with purified granule cells, suggesting that dendritic spines form only in the presence of granule cell afferents, contrary to the conclusions drawn from the earlier in vivo studies. The spines that formed in the culture experiment were reported to synapse with parallel fibers.

Parasagittally oriented organotypic cerebellar cultures derived from newborn mice develop many features of the cerebellum in vivo /24/. The five major types of cortical neurons are represented in vitro and form the expected interneuronal relationships, so that the granule cells, the only excitatory cortical neurons, project to all other cortical neurons, including Purkinje cells and the inhibitory interneurons, the basket, stellate, and Golgi cells. Purkinje cells, the only neurons whose axons project from the cortex, innervate the target deep nucleus neurons, which are incorporated in all cerebellar explants except those derived from the midline, where there is no underlying deep nucleus, while recurrent axon collaterals are projected to all other cortical neurons, including other Purkinje cells. Extracerebellar afferents are usually absent, except in occasional cultures with incorporated fragments of dorsal pontine tissue, in which case some mossy fibers are present and synapse with granule cell dendrites to form glomeruli, as seen in vivo, and with Golgi cell somata and dendrites /24/. The usual neuron-glia interactions also develop in vitro, so that the cultures become myelinated and the Purkinje cells become ensheathed by astrocytic processes.

When such cultures are exposed to the DNAsynthesis-inhibitor, cytosine arabinoside (Ara C), for the first 5 days in vitro (DIV), the granule cells and oligodendrocytes are either vastly reduced or destroyed, and surviving astrocytes are functionally compromised, so that they do not appose neuronal membranes 14,38/. Such cultures are not myelinated, the Purkinje cells lack their normal astrocytic sheaths, and their somata are hyperinnervated by recurrent axon collateral terminals. In the absence of granule cells, Purkinje cell dendritic spines form and are innervated by terminals of sprouted recurrent axon collaterals from other Purkinje cells. Some unattached Purkinje cell dendritic spines are present, most without postsynaptic densities, but they are far outnumbered by the spines forming heterotypical synapses with recurrent axon collaterals. Occasional mossy fibers, when present, form multiple synapses with Golgi cell dendrites in pseudoglomerular formations. In one study $/ 4 /$, mossy fibers were reported not to synapse with Purkinje cell dendritic spines, as has been described for in vivo cerebella after granule cell depletion $/ 1,15,19,40 /$.

Once this cortical reorganization has been achieved, the cultures can be "transplanted" with granule cells or glia or both to restore some or all the morphological characteristics of the standard culture preparation. The following is a review of a series of studies in which glia and granule cells have been replaced, either in combination or separately, in Ara-C-treated cultures lacking these elements, and what the following events have revealed about Purkinje cell dendritic spine formation. Additional changes that occur as a result of manipulating these culture models are described in a more extensive review $/ 28 /$.

\section{MATERIALS AND METHODS}

Organotypic cerebellar cultures, such as those described above, were prepared from newborn (within $24 \mathrm{hr}$ after birth) Swiss-Webster mice by 
isolating the cerebellum from the underlying pons by sectioning the cerebellar peduncles as close as possible to the cerebellum, trimming and discarding the lateral ends, and then cross-cutting the cerebellum in the parasagittal plane with scalpel blades into 7 or 8 sections 0.5 -mm-thick $/ 5,24,26 /$. Each section was placed on a collagen-coated coverslip with a drop of nutrient medium, incorporated into a Maxinow assembly, and incubated in the lying-drop position at $35.5-36^{\circ} \mathrm{C}$. The nutrient medium was initially changed at 5 DIV, and twice weekly thereafter. The standard medium consisted of 2 parts $3 \mathrm{IU} / \mathrm{ml}$ low-zinc insulin, 1 part $20 \%$ dextrose, 8 parts Eagle's minimum essential medium with added L-glutamine 7 parts Simms' X-7 balanced salt solution with incorporated HEPES buffer ( $\mathrm{pH} 7.4$ ) to make its concentration $10^{-2}$ in the fully constituted medium, and 12 parts fetal calf serum. For Ara C-treated cultures, the Ara $\mathrm{C}$, at a concentration of $5 \mu \mathrm{g} / \mathrm{ml}$ medium, was incorporated into the nutrient medium at explantation, and after a 5-day exposure, the cultures were maintained in standard medium $/ 38 /$.

Transplantation of Ara C-treated cerebellar cultures was accomplished by superimposing onto the host explants, at 8-9 DIV or later, tissue containing the cellular components to be added. Granule cells plus glia were added in the form of 9-DIV cerebellar explants exposed for the first 5 DIV to nutrient medium with incorporated $10^{-4} \mathrm{M}$ kainic acid, which destroyed all cortical and subcortical neurons except granule cells, which are selectively resistant to kainate, and left the glia intact $/ 33 /$. The kainic acid-exposed cultures were removed from their collagen substrates and placed directly on the Ara C-treated host cultures under a dissecting microscope. The transplant pairs were maintained in standard medium $137 /$. Glia alone were added in the form of fragments of 7-day-old mouse optic nerve $/ 16,17 /$. Granule cells, in the absence of functional glia, were introduced to host Ara C-treated explants in the form of cerebellar cultures exposed for the first 5 DIV to kainic acid to eliminate all neurons but granule cells, followed by 4 days of exposure to Ara $\mathrm{C}$ to destroy or to compromise the glia $/ 27 /$. Such preparations were dissected from their collagen substrates at 9 DIV and superimposed on 9 DIV Ara C-treated cultures in the same fashion as described above. Attempts had been made to apply suspensions of dissociated, purified granule cells to Ara C-exposed cerebellar cultures, but the cells could not be sufficiently concentrated over the explants, and trials with pelleted granule cells were unsuccessful because the cells were unable to migrate from the pellets.

\section{RESULTS}

\section{Transplantation with granule cells and glia}

In the initial studies of transplantation of Ara Ctreated cerebellar cultures with granule cells and glia, the cultures were inspected daily in the living state for signs of myelination and were fixed and stained for light microscopic and ultrastructural observations 10 days after superimposing the kainate-exposed explants $13,37 /$. Myelination was evident in $78 \%$ of transplanted Ara C-treated cultures, 3-5 days post transplantation (DPT), which compares with $80 \%-85 \%$ for untreated, control cerebellar cultures. At $10 \mathrm{DPT}$, granule cells were abundantly present in the cortex, and the density of cortical neurites was similar to that of the control explants, representing a reduction of the sprouted recurrent axon collaterals. Purkinje cells had acquired astrocytic sheaths, axosomatic synapses were reduced, and most Purkinje cell dendritic spines had formed homotypical synapses with parallel fiber terminals. Occasional mossy fibers formed multiple synapses with granule cell dendrites to form true glomeruli, which replaced the pseudoglomeruli, characteristic of Ara C-treated cultures with incorporated fragments of dorsal pons.

From the observations at $10 \mathrm{DPT}$, it was not possible to determine if the newly formed homotypical parallel fiber-Purkinje cell dendritic spine synapses were with dendritic spines already present but vacated by withdrawing or degenerating recurrent axon collateral terminals, or with newly developed dendritic spines. Insight into this question was gained from a recent study $/ 29 /$, in which cultures were examined daily by electron microscopy after transplantation. Homotypical synapses were first evident at 2 DPT in areas of the cortex in which "established" Purkinje cell dendritic spines were present without any indication of new 


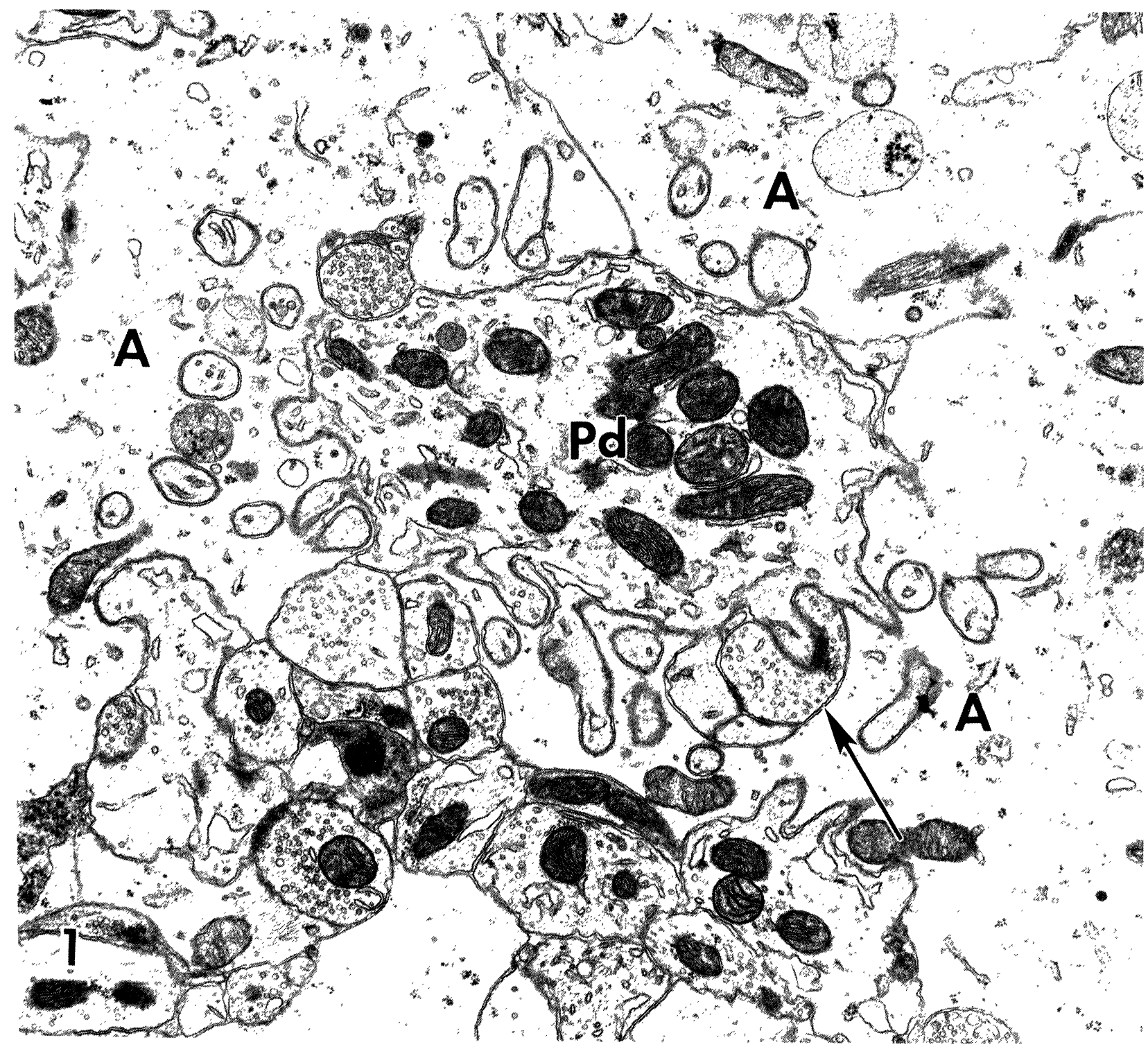

Fig. 1 Electron micrograph from the cortex of a 13 days in vitro (DIV) cytosine arabinoside (Ara C)-treated cerebellar culture 4 days post transplantation (DPT) with granule cells and glia. A Purkinje cell dendrite (Pd) is shown surrounded by proliferated dendritic spines, most of which are unattached and embedded in astrocytic processes (A). The arrow points to a presumptive parallel fiber terminal that has formed an asymmetric synapse with one spine and is in nonsynaptic contact (in this plane of section) with two others. $\times 18,000$ 
spine formation. Also evident at 2 DPT in scattered cortical regions were areas of Purkinje cell dendritic spine proliferation. These spines were unattached and were usually in the vicinity of astrocytic processes. Over the next several days, the spine proliferation continued and accelerated, and an example of dendritic spine proliferation at $4 \mathrm{DPT}$ is shown in Fig. 1, when many of the unattached spines were encased in astrocytic processes. At 4 DPT the earliest synapses with newly formed spines were noted, and presumptive parallel fiber terminals often synapsed with or contacted more than one dendritic spine (Fig. 1). Synapse formation among clusters of newly proliferated spines subsequently increased, as shown in Fig. 2 from a culture at $6 \mathrm{DPT}$. By $7 \mathrm{DPT}$, the numbers of clusters of unattached dendritic spines appeared reduced, as the synapse formation with newly proliferated spines continued, and by 9 DPT such clusters were sparse. An example of residual spine clusters encircled by Purkinje cell dendrites at 8 DPT is shown in Fig. 3 (compare with Fig. 14 in /40/ and Fig. 39 in /1/ illustrating similar formations in a weaver mutant mouse and an X-irradiated rat). Spine clusters were not noted in our original study at $10 \mathrm{DPT} / 3 /$, probably because of their absence or infrequent occurrence.

The results of the serially timed ultrastructural study suggested that axons from granule cells transplanted to host Ara C-treated cultures synapsed with both established and newly formed Purkinje cell dendritic spines, as two patterns of homotypical synapse development were evident, one beginning early (2 DPT) in cortical areas without dendritic spine proliferation and another beginning later (4 DPT) in areas with proliferated spines. The results of the timed study also indicated that clusters of proliferated dendritic spines disappeared as synapse formation with parallel fiber terminals progressed.

\section{Transplantation with glia}

Transplantation of Ara C-treated cerebellar cultures with fragments of mouse optic nerve resulted in myelination of $53 \%$ of the host cultures $125 /$ and no appreciable reduction of sprouted recurrent axon collaterals $/ 16 /$. Purkinje cells acquired astrocytic sheaths, and axosomatic synapses were reduced /17/. Cortical neuropil synapses were reduced in transplanted cultures, and clusters of unattached Purkinje cell dendritic spines were present in cortical regions from 8-22 DPT during the entire observation period /16/. Most spines in the clusters were not in direct contact with astrocytic processes. This observation, plus the clustering pattern, suggested the induction of spine proliferation in local regions of the dendritic processes by a diffusible factor secreted by glia. Spine proliferation was not observed in Ara Ctreated cerebellar explants transplanted with purified, dissociated oligodendrocytes, where the only significant change was myelination $/ 36 /$. Purkinje cell dendritic spine proliferation, however, was induced in Ara C-treated cultures by exposure to an astrocyte-conditioned medium $/ 34 /$, thus linking this phenomenon to astrocytes.

The results of these studies showed that Purkinje cell dendritic spine proliferation was induced in Ara C-treated cultures by addition of glia or by exposure to astrocyte-conditioned medium. In neither condition were granules cells present. Moreover, in the absence of granule cells, clusters of proliferated, unattached dendritic spines persisted in the cultures throughout the period of observation, contrary to their disappearance in Ara C-treated cultures transplanted with glia and granule cells, in which many of the newly formed spines were occupied by parallel fiber terminals.

\section{Transplantation with granule cells}

In the final condition that we examined, in which Ara C-treated cerebellar explants were transplanted with cultures containing granule cells and either functionally compromised or absent glia, myelination was not evident in host cultures at 6 DPT, and cortical neurites were not reduced to control levels because twice as many heterotypical recurrent axon collateral-Purkinje cell dendritic spine synapses persisted when competent astrocytes were not included in the graft $/ 27 /$. Purkinje cells were not ensheathed by astrocytic processes, and their somata remained hyperinnervated by recurrent axon collateral terminals. Homotypical parallel fiber-Purkinje cell dendritic spine synapses were evident at $6 \mathrm{DPT}$, as in cultures transplanted with granule cells and glia, but no clusters of proliferated 


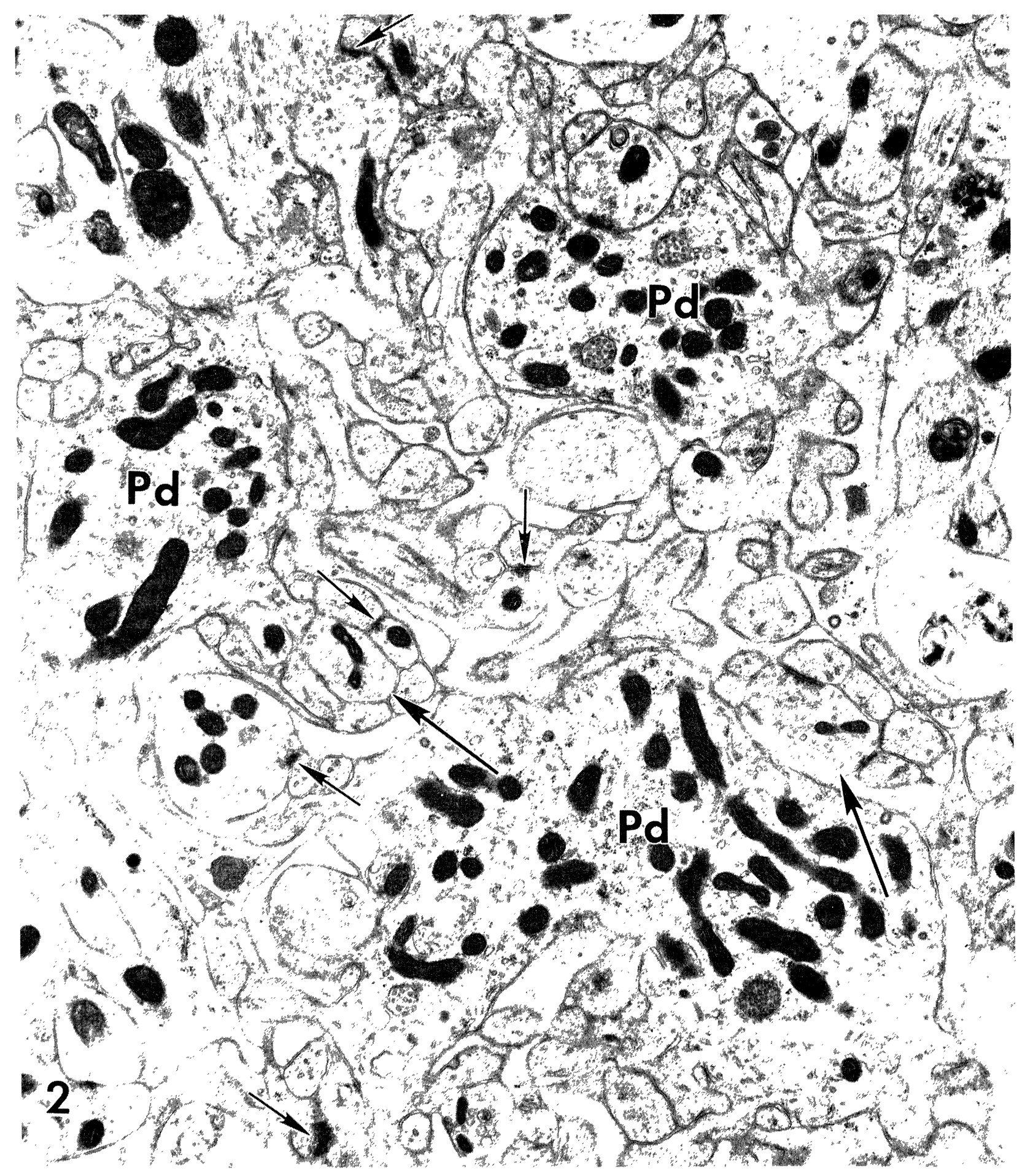

Fig. 2. Cortical neuropil from a 15 DIV Ara C-exposed cerebellar culture 6 DPT with granule cells and glia. Three Purkinje cell dendrites (Pd) are surrounded by dendritic spines, some of which have formed asymmetric synapses with parallel fiber terminals (small arrows), as synapse formation with proliferated spines has increased. The large arrows indicate presumptive parallel fiber terminals that have synapsed with or contacted multiple dendritic spines. Such formations appear to be intermediate to a later stage at which a 1:1 ratio of parallel fiber terminals to Purkinje cell dendritic spines is predominant. $\times 18,000$ 


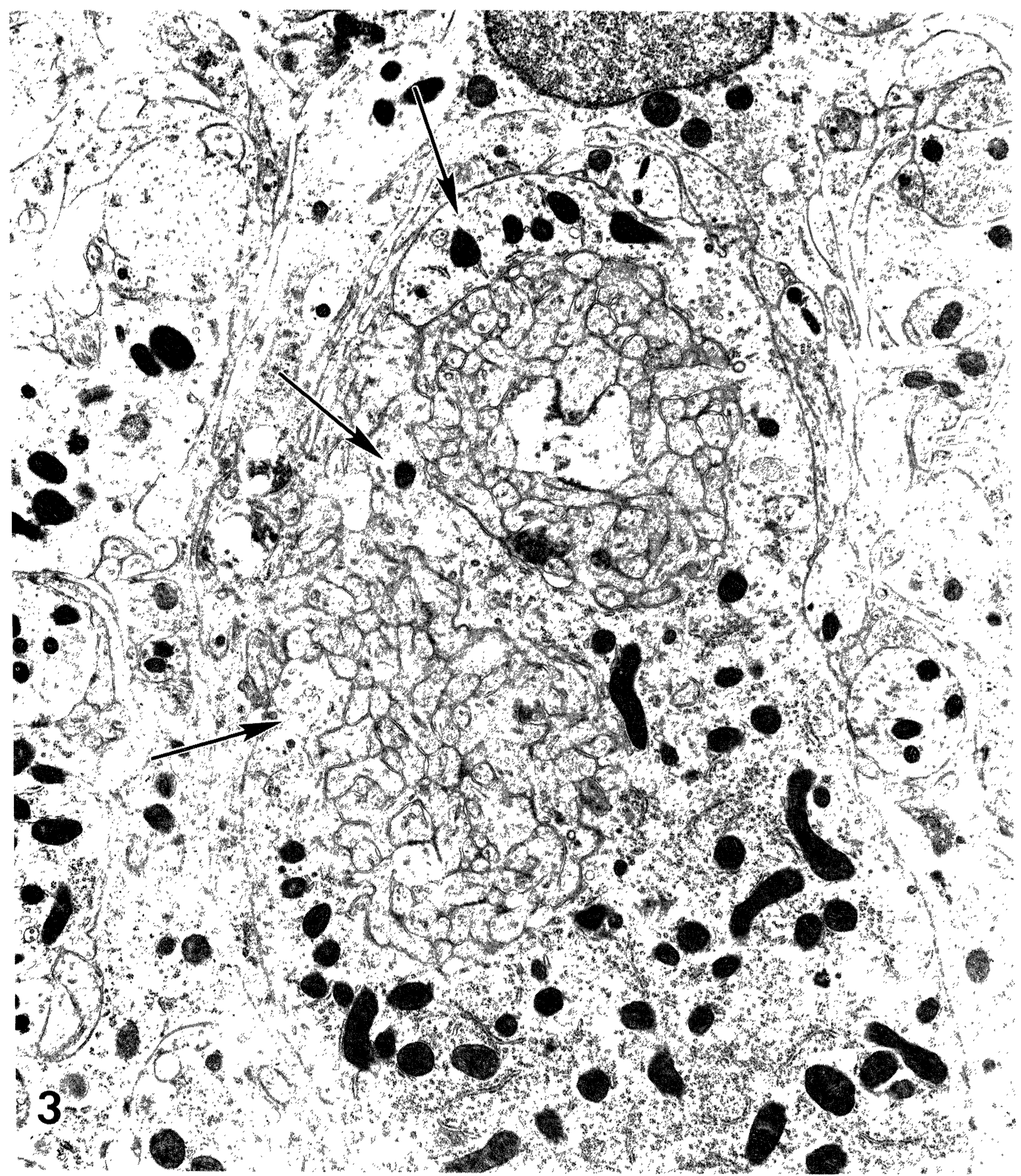

Fig. 3. Cortical neuropil from a 17 DIV Ara C-treated cerebellar explant 8 DPT with granule cells and glia. The arrows point to three Purkinje cell dendritic processes surrounding two residual clusters of proliferated dendritic spines, which are now infrequently present. Most of the spines are without presynaptic elements. $\times 12,000$ 
dendritic spines were observed in the absence of functional astrocytes.

In this study it was shown that granule cells alone did not induce clusters of proliferated Purkinje cell dendritic spines in this culture system. New spines may have formed and may have been quickly occupied by parallel fiber terminals, but clusters of unattached spines were not observed at $6 \mathrm{DPT}$, as they were when Ara C-treated cultures were transplanted with both granule cells and glia (Fig. 2). The results of this particular study do not rule out the induction of Purkinje cell dendritic spine formation by granule cell afferents but suggest that such spines are formed less profusely than when competent astrocytes are present.

\section{DISCUSSION}

The key experiments in this series of studies identifying a source of Purkinje cell dendritic spine induction are those in which Ara C-treated Purkinje cells without granule cells were transplanted with glia alone or were exposed to astrocyte-conditioned medium $/ 16,34 /$. In both instances there was a profuse proliferation of dendritic spines that, in the absence of granule cells, remained unattached by presynaptic elements and persisted in the cultures. These results suggest that Purkinje cell dendritic spine proliferation, at least under these circumstances, is induced by an astrocyte-secreted factor. Studies are underway to establish the identity of the factor.

This notion is not inconsistent with the findings often reported and illustrated in the earlier in vivo studies of agranular cerebella, in which unattached Purkinje cell dendritic spines were enveloped by astrocytic processes $/ 1,10-15,19,21,39,40 /$. The arguments presented in favor of an autonomous induction of dendritic spines by Purkinje cells included ultrastructural observations at timed intervals of dendritic spine development in the absence of parallel fibers $/ 21 /$. The concept of glial induction of the spines was not considered at that time because of the focus on induction by presynaptic elements. The findings presented in the in vivo studies, however, are not contrary to the possibility that Purkinje cell dendritic spine formation could be induced by astrocytes. On the other hand, dendritic spines are present in Ara Ctreated cultures, in which astrocyte function is compromised-at least by $6 \mathrm{DIV} / 35 /$, but the functional state of astrocytes earlier than that is less clear-so that autonomous induction may also be a factor during development.

This leaves the apparently contradictory results that were obtained with dissociated purified cell cultures, in which Purkinje cell dendritic spines were formed only when granule cells were present 12/. Several explanations are possible. One explanation is that the cell-culture study dealt with the issue of the initial formation of dendritic spines during development, whereas in our studies with organotypic cultures, Purkinje cell dendritic spines were already present at the time of transplantation or of exposure to astrocyte-conditioned medium, so that additional spines were induced on a background of already formed spines. The signals for the initial induction of spines during development conceivably could be different from those for postdevelopmental spine induction, as already alluded to in the previous paragraph. The results of the in vivo studies, in which dendritic spine development was observed in the absence of parallel fibers, argue in favor of a mechanism not involving granule cells, but neither these studies nor our culture studies rule out a role for dendritic spine induetion by granule cells when such cells are present.

Another possible explanation is that the requirements for dendritic spine induction differ in "connected" versus isolated Purkinje cells. In both Ara C-treated cultures and agranular cerebella in vivo, Purkinje cells, in the absence of parallel fibers, receive afferent input from other cortical neurons and send efferent projections to target deep nucleus neurons and other cortical neurons. Purkinje cells grown in isolation have only other Purkinje cells as targets or as an afferent source, and such contacts have been described in the isolated culture situation $12 /$. Critical factors, such as neurotrophic factors, may be missing in isolated Purkinje cell cultures, one consequence of which may be to disallow dendritic spine induction in response to the usual signals, but which can be overcome by adding another afferent source, such as granule cells, that may have a capacity for dendritic spine induction. This possibility could be tested by exposing isolated 
Purkinje cells to a combination of all other cortical components but granule cells.

A third possibility relates to properties that cells grown in isolation may acquire, as opposed to factors that are missing from their environment. For example, isolated oligodendrocytes have been reported to make myelin-like membranes in the absence of axons $/ 6,20 /$, a property that they retain even after transplantation to cultures with myelinreceptive axons, which are also myelinated $/ 36 /$. By contrast, oligodendrocytes that are maintained as part of an explant culture do not demonstrate this degree of hyperactivity, even when used as a graft $13 /$. In dissociated cultures of whole cerebellum, Purkinje cells develop complex dendrites $/ 2,23 /$, but the dendrites are elongated and minimally branched when cultured with neuronal-activity-blocking agents $/ 23 /$. Such aberrant dendrites are not evident in Ara C-treated or otherwise untreated organotypic cerebellar cultures that have been maintained since explantation in medium containing activity-blocking agents $130,31 /$, which may reflect an intrinsic difference in Purkinje cells that are cultured by these different methods. Cultivation of cells in isolation may sufficiently alter their properties so that extrapolating to similar cells in vivo the results obtained with such preparations presents some difficulties.

With regard to neuronal activity, Purkinje cell dendritic spine formation was evident in both Ara C-treated and otherwise untreated organotypic cerebellar cultures chronically exposed to activityblocking agents (a combination of tetrodotoxin and elevated levels of $\mathrm{Mg}^{++}$) $/ 30,31 /$. Moreover, parallel fiber-Purkinje cell dendritic spines developed as well in the absence of neuronal activity as they did in cultures with endogenous cortical activity when Ara C-treated cultures were transplanted with granule cells and glia, suggesting that neuronal activity was not necessary for forming these synapses $/ 32 /$. The synapses that were reduced as a consequence of activity blockade were inhibitory synapses, and not excitatory parallel fiberPurkinje cell dendritic synapses $/ 30,32 /$.

What purpose might astrocytic induction of Purkinje cell dendritic spines serve? Astrocytes are multifunctional cells (reviewed in /7,8/). Among their properties is the production of diffusible neurite growth-promoting factors $/ 18,22 /$. During development, astrocytes appear to guide the directional growth of axons to their targets within the central nervous system /9/. An associated function may be to prepare the target neurons for the arrival of the axons by expansion of the postsynaptic sites on target dendrites. A similar astrocytic function may be part of a response to postdevelopmental injury. Secretion of a factor that promotes dendritic spine proliferation might ensure the availability of sufficient numbers of postsynaptic sites for synapse formation with potentially regenerating axon terminals and reconstruction of the normal circuitry.

\section{ACKNOWLEDGMENTS}

Studies from the author's laboratory were supported by the U.S. Department of Veterans Affairs and National Institutes of Health grant NS 17493. I thank Juany C. Rehling for help with the illustrations.

\section{REFERENCES}

1. Altman J, Anderson WJ. Experimental reorganization of the cerebellar cortex. I. Morphological effects of elimination of all microneurons with prolonged X-irradiation started at birth. J Comp Neurol 1972; 164: 355-403.

2. Baptista CA, Hatten ME, Blazeski R, Mason CA. Cellcell interactions influence survival and differentiation of purified Purkinje cells in vitro. Neuron 1994; 12: 243-260.

3. Blank NK, Seil FJ. Reorganization in granuloprival cerebellar cultures after transplantation of granule cells and glia. II. Ultrastructural studies. J Comp Neurol 1983; 214: 267-278.

4. Blank NK, Seil FJ, Herndon RM. An ultrastructural study of cortical remodeling in cytosine arabinoside induced granuloprival cerebellum in tissue culture. Neuroscience 1982; 7: 1509-1531.

5. Bornstein MB, Murray MR. Serial observations on patterns of growth, myelin formation, maintenance, and degeneration in cultures of newborn rat and kitten cerebellum. J Biophys Biochem Cytol 1958; 4: 499504.

6. Bradel EJ, Prince FP. Cultured neonatal rat oligodendrocytes elaborate myelin membrane in the absence of neurons. J Neuroscience Res 1983; 9: 381-392

7. Fedoroff S, Vernadakis A, eds. Astrocytes, Vol. 2. Cell Biochemistry, Physiology, and Pharmacology of Astrocytes. Orlando: Academic Press, 1986. 
8. Fedoroff S, Vernadakis A, eds. Astrocytes, Vol. 3. Cell Biology and Pathology of Astrocytes. Orlando: Academic Press, 1986.

9. Hankin MH, Silver J. Mechanisms of axonal guidance. In: Browder LW, ed, Developmental Biology, Vol. 2. New York: Plenum, 1986; pp. 565-604.

10. Herndon RM. Thiophen-induced granule cell necrosis in the rat cerebellum. An electron microscopic study. Exp Brain Res 1968; 6: 49-68.

11. Herndon RM, Margolis G, Kilham L. The synaptic organization of the malformed cerebellum induced by perinatal infection with the feline panleukopenia virus (PLV). II. The Purkinje cell and its afferents. J NeuroPathol Exp Neurol 1971; 30: 557-570.

12. Hirano A, Dembitzer HM. Cerebellar alterations in the weaver mouse. J Cell Biol 1973; 56: 478-486.

13. Hirano A, Jones M. Fine structure of cycasin-induced cerebellar alterations. Fed Proc 1972; 31: 1517-1519.

14. Hirano A, Dembitzer HM. Jones M. An electron microscopic study of cycasin-induced cerebellar alterations. J Neuropathol Exp Neurol 1972; 31: 113-125.

15. Llinás $R$, Hillman $D E$, Precht $W$. Neuronal circuit reorganization in mammalian agranular cerebellar cortex. J Neurobiol 1973; 4: 69-94.

16. Meshul CK, Seil FJ. Transplanted astrocytes reduce synaptic density in the neuropil of cerebellar cultures. Brain Res 1988; 441: 23-32.

17. Meshul CK, Seil FJ. Astrocytes play a role in regulation of synaptic density. Brain Res 1987; 402: 139-145.

18. Miller RH, Smith GM. Cell and molecular interactions that influence astrocytè-mediated axon outgrowth. In: Seil FJ, ed, Advances in Neural Regeneration Research, Neurology and Neurobiology, Vol. 60. New York: Wiley-Liss, 1990; pp. 171-183.

19. Oster-Granite ML, Herndon RM. The pathogenesis of parvovirus-induced cerebellar hypoplasia in the Syrian hamster, Mesocricetus auratus. Fluorescent antibody, foliation, cytoarchitectonic, Golgi, and electron microscopic studies. J Comp Neurol 1976; 169: 481-521.

20. Poduslo SE, Miller K, Wolinsky JS. The production of a membrane by purified oligodendroglia maintained in culture. Exp Cell Res 1982; 137: 203-215.

21. Rakic P, Sidman RL. Organization of cerebellar cortex secondary to deficit of granule cells in weaver mutant mice. J Comp Neurol 1973; 152: 133-161.

22. Rudge JS, Manthorpe M, Varon S. The output of neurotrophic and neurite-promoting agents from rat brain astroglial cells: A microculture method of screening potential regulatory molecules. Dev Brain Res 1985; 19: 161-172.

23. Schilling K, Dickinson MH, Connor JA, Morgan JI. Electrical activity in cerebellar cultures determines Purkinje cell dendritic growth patterns. Neuron 1991; 7: 891-902.

24. Seil FJ. Cerebellum in tissue culture. In: Schneider DM, ed, Reviews of Neuroscience, Vol. 4. New York:
Raven Press, 1979: pp. 105-177.

25. Seil FJ. Tissue culture models of myelination after oligodendrocyte transplantation. J Neural Transplant Plast 1989; 1: 49-55.

26. Seil FJ. Organotypic neural cultures. In: Tyson CA, Frazier JM, eds, In Vitro Biological Systems: Preparation and Maintenance (Methods in Toxicology, Vol. 1). Orlando: Academic Press, 1993; pp. 7-26.

27. Seil FJ. Persistence of heterotypical synapses in transplanted cerebellar cultures in the absence of functional glia. Int J Dev Neurosci 1994; 12: 411-421.

28. Seil FJ. Neural plasticity in cerebellar cultures Progress in Neurobiology (in press).

29. Seil FJ. Serial changes in granuloprival cerebellar cultures after transplantation with granule cells and glia: A timed ultrastructural study. Neuroscience (in press).

30. Seil FJ, Drake-Baumann R. Reduced cortical inhibitory synaptogenesis in organotypic cerebellar cultures developing in the absence of neuronal activity. J Comp Neurol 1994; 342: 366-377.

31. Seil FJ, Drake-Baumann R. Circuit reorganization in granuloprival cerebellar cultures in the absence of neuronal activity. J Comp Neurol 1995; 356: 552-562.

32. Seil FJ, Drake-Baumann R. Activity-dependent changes in "transplanted" cerebellar cultures. Exp Neurol 1996: 138 327-337.

33. Seil FJ, Blank NK, Leiman AL. Toxic effects of kainic acid on mouse cerebellum in tissue culture. Brain Res 1979; 161: 253-265.

34. Seil FJ, Eckenstein FP, Reier PJ. Induction of dendritic spine proliferation by an astrocyte-secreted factor. Exp Neurol 1992; 117: 85-89.

35. Seil FJ, Herndon RM, Tiekotter KL, Blank NK. Reorganization of organotypic cultures of mouse cerebellum exposed to cytosine arabinoside: A timed ultrastructural study. J Comp Neurol 1991; 313: 193212.

36. Seil FJ, Johnson ML, Saneto RP, Herndon RM, Mass MK. Myelination of axons within Ara C-treated mouse cerebellar explants by cultured rat oligodendrocytes. Brain Res 1989; 503: 111-117.

37. Seil FJ, Leiman AL, Blank NK. Reorganization in granuloprival cerebellar cultures after transplantation of granule cells and glia. I. Light microscopic and electrophysiological studies. J Comp Neurol 1983; 214: 258-266.

38. Seil FJ, Leiman AL, Woodward WR. Cytosine arabinoside effects on developing cerebellum in tissue culture. Brain Res 1980; 186: 393-408.

39. Sotelo C. Permanence and fate of paramembranous synaptic specializations in 'mutants' and experimental animals. Brain Res 1973; 62: 345-351.

40. Sotelo C. Anatomical, physiological and biochemical studies of the cerebellum from mutant mice. II. Morphological study of cerebellar cortical neurons and circuits in the weaver mouse. Brain Res 1975; 94: 19. 

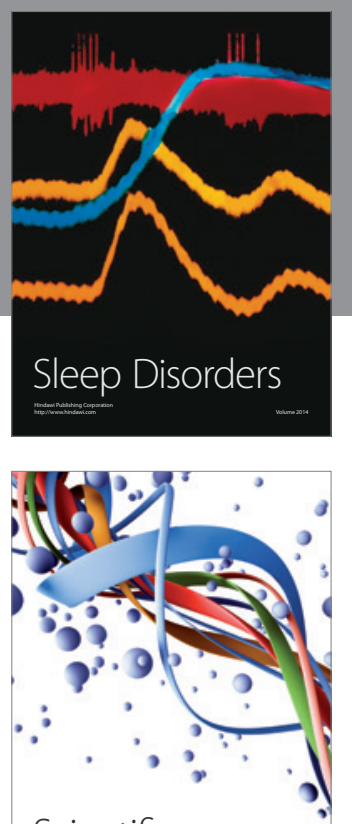

Scientifica
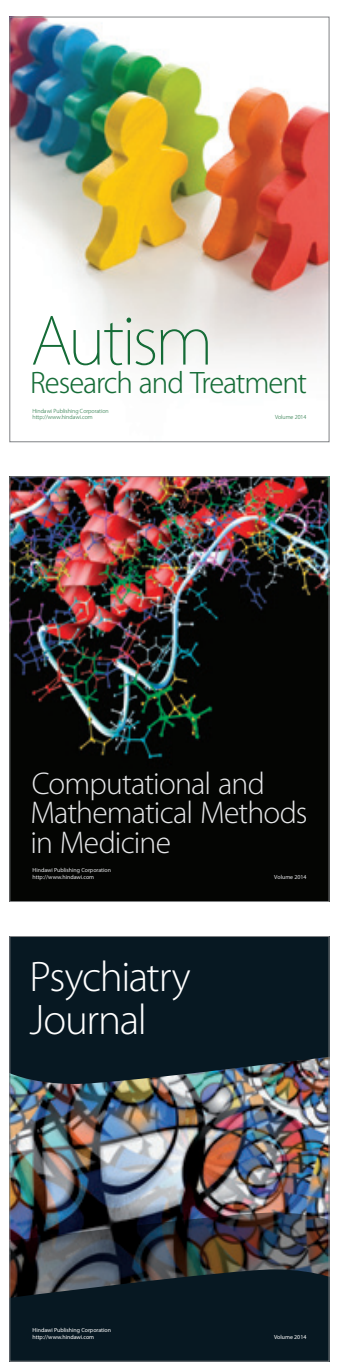
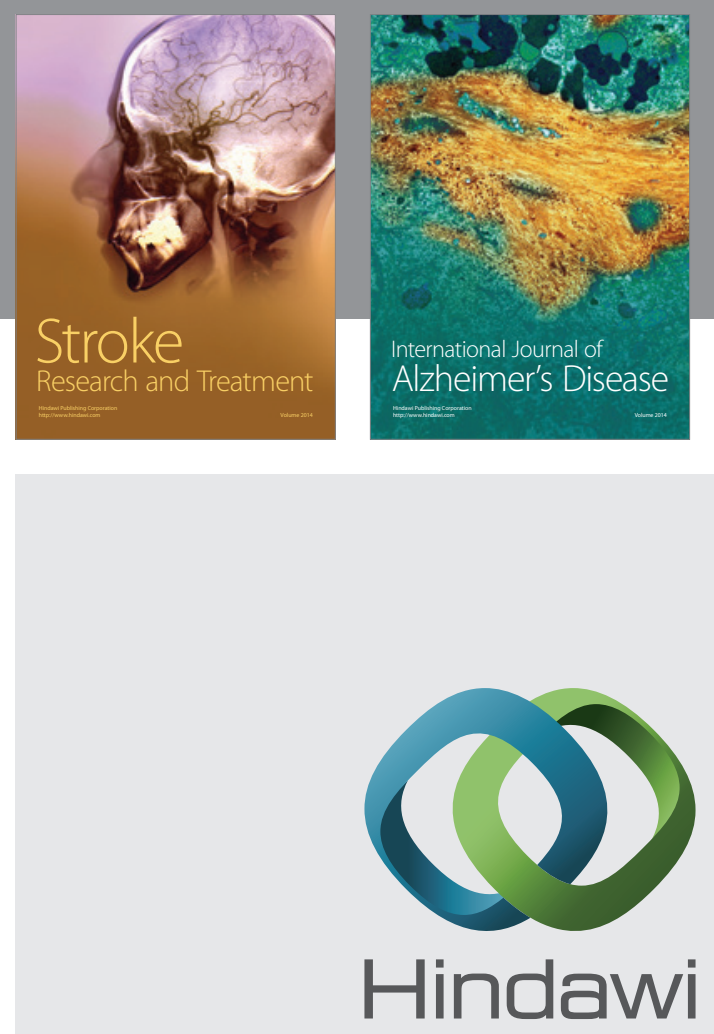

Submit your manuscripts at

http://www.hindawi.com
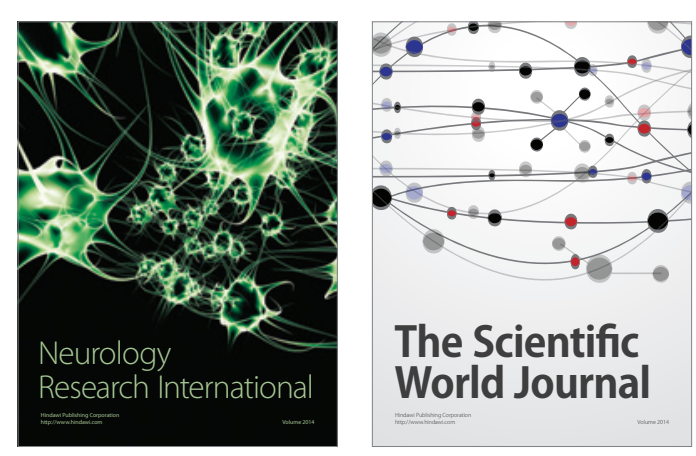

The Scientific World Journal

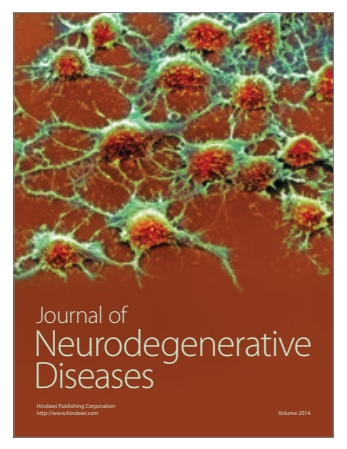

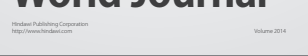

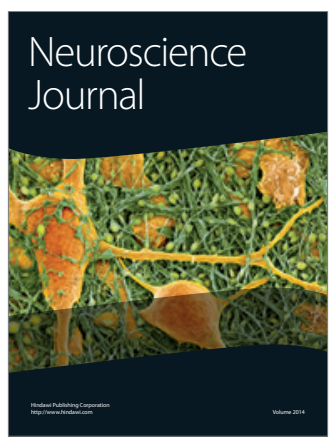

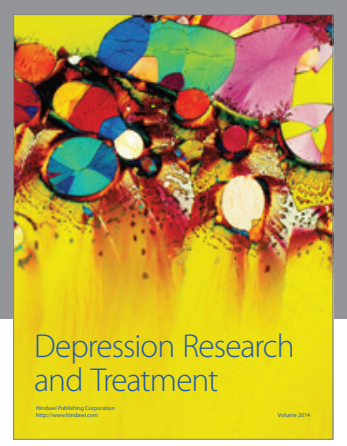
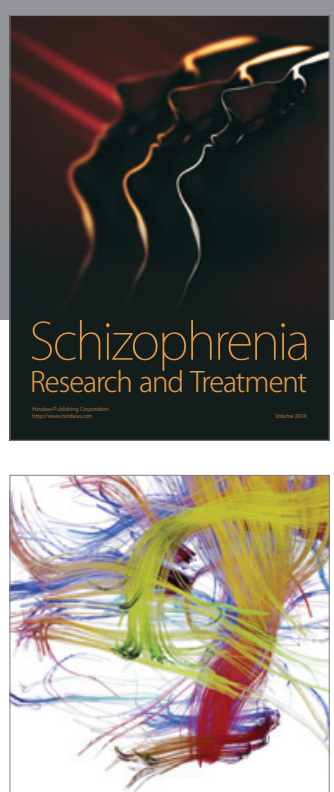

Brain Science

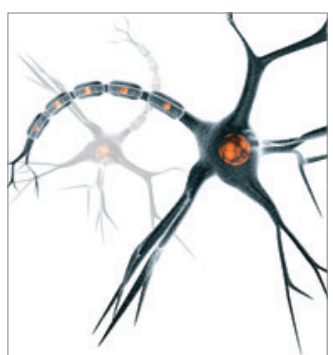

Neural Plasticity
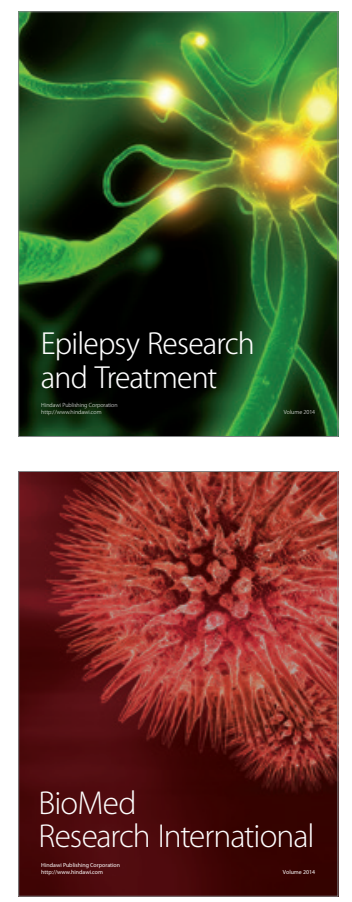

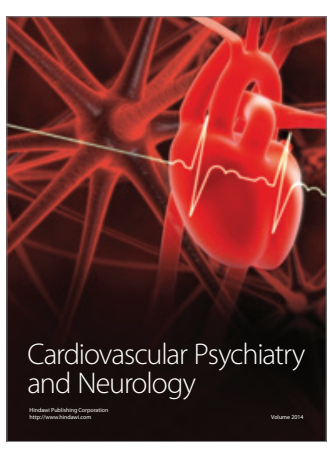

Parkinson's

Disease
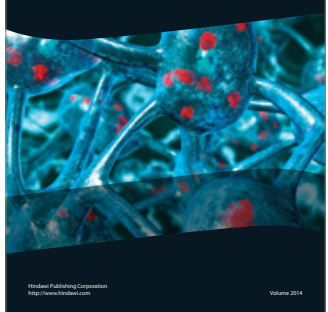